\title{
Study on Shaman Semiotics of Olunchun Ethnic Group
}

\author{
Lili Song \\ Heihe University \\ Heihe, China 164300 \\ Institute of Education \\ Xiamen University \\ Xiamen, China 361005
}

\author{
Dong Zou \\ Heihe University \\ Heihe, China 164300
}

\begin{abstract}
The Shamanism is a worldwide primitive religion, formed the profound cultural system, and widely spread in the Olunchun, the Shamanism is the key research object on cultural science, ethnology, psychology and semiotics. As Mr \&matrimonial chemical products, Shamanism symbols is an important medium of sa \&matrimonial dissemination and inheritance, there is a very rich cultural connotation, expressing the ancients of nature's most simple ideas and aspirations. The forms of the Olunchun Shaman symbols are various, including masks, pictures, texts, and artifacts, and the research value is inestimable. Based on the brief description of the origin of Shaman culture, this paper focuses on the study of Shaman semiotics in Olunchun.
\end{abstract}

Keywords-Olunchun nationality; Shaman culture; Semiotics; aesthetic

\section{INTRODUCTION}

For most people, Shaman is a mysterious word that is often associated with feudal superstitions. In fact, Shamanism is the core of the Shaman culture, which has a long history. According to archaeological speculation, it was produced more than 14,000 years ago and remains in the Olunchun family. In a sense, $\mathrm{Mr} \&$ matrimonial is the source of many cultures around the world, its unique way of information recording, transmission, become the surviving long ancient civilization, reflecting the evolution of the human cognition of nature, its research value can't be measured easily. At present, there are many studies on the Shaman semiotics of Olunchun, which provides support for people to better understand the Shaman culture.

\section{SHAMAN CULTURE}

Shaman is a word derived from the Tungusic language saman and the north American Indian shamman, which means the wise, the young, the exploration, etc., and gradually becomes the Shaman, who is understood as the incarnation of Shaman. According to relevant historical records, the Shaman culture originated from the ancient hunting culture period and was produced more than 14,000 years ago. Shamanism is widely distributed, and has been believed by many ethnic groups in northeast Asia, North America and northern Europe, and has been spread in northern China. Taking the Olunchun family as an example, it has a long history of carrying on the culture of Shamanism, and it still has some contents of belief, and probes into the magic phenomenon and power in nature. The scholar $\mathrm{Lu}$ Daji believes that Shamanism is different from people's religion, and its fundamental purpose is to satisfy people's real life needs, so Shaman symbols are mainly supported by living materials. In primitive times, due to the low social productive forces, out of the fear of the unknown world, people need a way which can explain natural strange phenomenon or power, such as physical, thrive, $\mathrm{Mr}$ \&matrimonial itself with great utility. In addition, the Shaman does respect the life. They believe that all things have spirit worship many gods, consciously abide by certain moral norms, including ethics, sincere, your word, got the parish of broad support and trust.

\section{The Olunchun SHAman SYMBOL}

The symbol is the materialized representation of the ideological concept of the Olunchun ethnic group, which reflects the thinking concept of certain groups and has very rich connotations and aesthetic semantics. From the history of the development of the Shaman culture in Olunchun, all thoughts will be put into practice and expressed as symbols. Based on the above background cognition, the author studies the Shaman semiotics from the four aspects of connotation, characteristics, aesthetics and application, and the specific expressions are as follows:

\section{A. Connotation}

The Shaman symbol system has rich connotations, which is an important way to explore the prehistoric culture of Olunchun. From the perspective of history, the material basis of Shaman symbols is the primitive nomadic economy, and is influenced by people's concept of life. However, no matter how the Shaman culture concept changes, it is through the record symbol processing and dissemination, and with the development attached to the abnormally rich connotation, the two are closely linked. According to semiotics, the Shaman culture system is undoubtedly a combination of various symbols. The basis of religious belief, according to Mircea Iliad, is that the religious experience is constructed through 
symbolism, by combining the various aspects of the subject into a cosmological whole. Therefore, there is a corresponding symbolic meaning behind each Shaman symbol, such as the symbol of status and the supreme power. As the embryo of primitive culture, the symbol culture shows the human thought concept and records the trajectory of early human behavior, so as to understand the communication information and thoughts and feelings of the ancestors. In the process of human social development, Olunchun Shaman symbol is effectively saved, bearing the original cultural change, to explore and understand ancient ancestors has very important value, the spirit of the rich connotation, but also enhance the aesthetic taste of modern people.

\section{B. Characteristics}

As mentioned above, Shaman symbols have rich connotations, which are the result of the materialization of Shaman's cultural ideology, and its diversified manifestations form a relatively complete symbol system. On the whole, the Shaman symbol of Olunchun has some obvious features. In particular, the Shaman symbols of the Olunchun ethnic group embody the nature worship, such as frogs, snakes, birds, trees, etc., reflecting the continuous cognition of the natural things in the long history of the ancestors of the Olunchun people. At the same time, the Shaman symbol of the Olunchun ethnic group also symbolizes the worship of the gods to express the blessing and relief of disasters, such as the god bless the travel and so on. Additionally, due to the prototype of living materials, the Shaman symbol of the Olunchun ethnic group has some practical functions, such as guiding and recording, etc. Shaman symbols from the initial form of the local natural environment or living demand, with distinct regional characteristics, such as reindeer Ewenki protection "Aaron god" accidentally, shows the Olunchun, to the attention of the reindeer was based on the needs of production and living. At that time, when the production level was low, people's exploration and cognition of nature formed the symbol of Shaman's natural worship, which played a certain guiding role in people's life. At the same time, as a kind of primitive form of information dissemination, interactive way, Olunchun people keep in touch with others by Shaman symbols, timely grasping the nature of the information and experience, in order to maintain the survival and development.

\section{Aesthetics}

In addition to the connotation semantics, the Olunchun Shaman symbol also has the aesthetic meaning, realizing the further spiritual sublimation. It can be said that the Shaman symbol of the Olunchun ethnic group is not only an important tool to record the world and have a better understanding of the world, but also a ladder to the art palace. Comprehensive interpretation of Olunchun Shaman symbol system, the relationship between the whole and local, in the form of the expression change and unity, symmetry and life, rhythm and tempo, such as aesthetic emotion, presents a kind of rhythm beauty and beauty. In fact, humans have psychological balance, when cannot meet, we just need to achieve the equilibrium on the vision by adjusting the inner factors such as gravity, direction, color change, many of this which can be found in Olunchun Shaman symbol. Long grass god, for example, the barbour day camp has two hands, one hand two pair of wild fruit plants, sides respectively followers a hand-held horsewhip attendants, presents a kind of symmetric balanced beauty. In addition, from the development of human civilization, as of the date of order is important to maintaining a healthy and stable social rules, so everywhere convey an invisible order aesthetic feeling, it also in Olunchun Shaman symbols are reflected, further strengthen the connotation of semantics. It is mainly composed of linear structure, combining with the balance of beauty and order, so that it has a unique visual appeal.

\section{Application}

In recent years, with the development of social economy, people's living standards continue to improve, the pursuit of spiritual becomes more strong, showed a keen interest in the design of rich local flavor and national characteristics. Based on such environmental background, a group of cultural and creative industries quietly emerged. As mentioned above, the rich connotations and aesthetic semantics of the Shaman symbols of the Olunchun ethnic group provide many inspirations for modern creative design. Continuously explore in humans and in the process of the cognition of the natural world, Mr \&matrimonial highly characteristic, the environmental protection and resource utilization of ideology, is in keeping with modern main trend of the development of the socialist era. For example, the patterns on the five finger gloves of the elunchun roe deer skin can be applied directly to the decoration design, which is conducive to enhancing its aesthetic emotion. In addition, the Olunchun Shaman symbols can be widely used in the design fields of orientation, animation, clothing and tourism products. In the era of knowledge innovation, in the face of fierce market competition, in order to attract consumers' eyeballs, product design should highlight individuality. As a result of its rich connotation and aesthetic semantic sedimentation, the Shaman symbol of Olunchun has provided a unique reference value for modern design. Objective dimension, Olunchun Shaman symbols and the integration of modern design, not only has the huge commercial value, at the same time is also the important means of sa \&matrimonial inheritance and development, its artistic value is immeasurable.

\section{THE CONCRETE IMAGE OF THE ETHNIC CUlture OF OLUNCHUN AND THE SHAMAN CULTURE}

Due to the awe of nature and the helplessness of human beings at low levels of productivity, the relationship between the ethnic culture of Olunchun and the Shaman culture is hidden, and the two are interlinked. Specifically, the Shaman culture, as the spiritual carrier of the Olunchun ethnic group, contains a variety of arts, which is the basis of the formation of the ethnic culture of Olunchun. The concrete representation of the ethnic culture of Olunchun and the culture of Shamanism is as follows: 


\section{A. Myths and Legends}

Under special historical conditions, the extremely low level of social productivity makes nature full of mystery. Oroqen ethnic myth and legend, is the earliest form of literature and art content about creation, human origins, shallow cognition to only according to their own original thinking to imagine the world, and thus derived a series of fairy tales, such as the well as created the Olunchun people ", the revised bhutto, he arranges the Shaman. Especially influenced by the Shaman culture, the myth and legends of the Olunchun people have appeared many powerful spirits and intelligent Shaman. In arranging the Shaman, Shaman is shaped proficiency characters, he is much higher than the perfect spirit of human, its to return the dead, often borne down, with the heaven and earth, Yin the world, and through communication with the gods, for the dead souls, to ease the suffering of the deceased loved ones, will be "good" lasting spreading, expressing the Oroqen nationality of yearning for life and hope. From such legends and legends, it is not difficult to see that Shaman culture has become a top priority in the ethnic culture of Olunchun and has played an important role in promoting its literary and artistic development.

\section{B. Music Poetry}

The Olunchun language belongs to the Altaic language family - Tungusic language branch, which has no written language, which is expressed by oral communication and expressed in folk songs, which is called "Shaman". The socalled "Shaman" refers to the songs sung by Shaman priests, including solo singing, singing, singing and singing. Based on the influence of Shaman culture, the Olunchun people have created rich and colorful spiritual culture in the long hunting life, such as music, poetry, dance, plastic arts and so on. Essence, "Shaman" still belongs to the category of folk songs, is not without its elements of folk songs, not fixed a unique religious music at the same time, its penetration in Oroqen ethnic culture is mainly manifested in jumping deer god ceremony. In the process, all the people in the village or tuen unit will be involved, led by Shaman, singing and chanting while singing. This special form of music is itself the inheritance of the Shaman culture, and also lays the foundation for the integration of the ethnic culture and the Shaman culture. From music art interpretation, the Olunchun national rap music, to Shaman culture is particularly significant. Among them, "mosu kun", as a common rap music form of the Olunchun ethnic group, is one of the earliest works. Over the course of specific process, the singer through dancing, role imitating tells the story, the characters show incisively and vividly, reflect the Shaman "all things have spirit" concept.

\section{Artistic Dance}

Among Shaman priests, dancing is regarded as one of the most important ways of divination. Through a series of movements of the gods, we communicate with god, convey the human aspiration, dispel evil spirits, and then pray for the prosperity of the tribe. With the rhythm of the drums, the sacrifice danced with the spirit, displaying the battle scenes between the wizard and the demon. Some of the high strength Shaman, can be the drum, waist bell sound and the foot dance moves in harmony, is a kind of aesthetic enjoyment. As a special form of culture and art, the song and dance carries the spiritual thoughts of the people of Olunchun, which contains its rich aesthetic taste and ideal. In the Shaman sacrificial dance, the fierce cry, the sound of drums, is similar to the "hewei" image of the Olunchun ethnic hunting, reproducing its original life form. Has come down, for example, the orogen nationality, the black bear fill bucket dance ", a comparatively intact the original totem consciousness and hunting, is the summary of the Oroqen nationality ancients knowledge rich experience, highlights the dance cultural charm. In Oroqen ethnic culture, in the form of dance simulation totem of expression, in please and close in performance, partly reflects its heritage and infiltration of the original $\mathrm{Mr}$ \&matrimonial is natural and deep.

\section{CONCLUSION}

All in all, the study of Shaman semiotics of Olunchun has very important cultural value, historical value and aesthetic value. The unique linear structure of the Olunchun Shaman has presented a kind of balanced beauty and rhythmic beauty, which reflects the process of human social cognition growth, and also has an enlightening effect on modern design., therefore, the author hopes all stay focused on the academic research, from the different dimensions of Olunchun Shaman semiotics, is to dig the connotation of semantic and aesthetic semantics, and organically combined with modern design, and maximize its artistic value at the same time, will be $\mathrm{Mr}$ \&matrimonial long live on and provide the audience with the rich aesthetic subject.

\section{ACKNOWLEDGEMENT}

This paper is a research project of Heilongjiang provincial philosophy and social science research project, "Investigation and protection research on the preservation of the Saman culture of Olunchun ethnic group in Heilongjiang province"

Approval number: Research results of 16MZE01.

\section{REFERENCES}

[1] Wang Tongxu. An interpretation of the semiotics of the "Nandehua" pattern of the Olunchun ethnic group [J]. Heilongjiang national series, 2017(05):150-154.

[2] Sun Huijia. Interpretation of the semiotics of the Shaman worship of the nomadic people in northern China [J]. Journal of Jilin art institute, 2015(05):7-11.

[3] Chen Jingmen. A brief analysis on the modeling and pattern patterns of Shaman costumes of Olunchun ethnic group [J]. Heilongjiang national series,2015(03):141-145.

[4] Zhang Jianping, Xu Ting. Discussion on the development and value of Shaman culture [J]. Shandong industrial technology,2014(22):265. 